\section{P84 THE IMPACT OF A MULTIDISCIPLINARY EDUCATIONAL PROGRAMME ON THE PRESCRIBING OF OXYGEN IN AN ACUTE TRUST}

doi:10.1136/thx.2010.150979.35

H Khachi, M Burman, L Walters, R Sinha-Ray, S Antoniou, S Mandal. Barts and the London NHS Trust, London, UK

Introduction and objectives Following the publication of the BTS guideline $^{1}$ and NPSA rapid response report ${ }^{2}$ on the use of oxygen, a multidisciplinary educational programme was developed to improve the prescription of oxygen in a large London teaching hospital. The aim of this project was to assess the impact of the educational programme.

Methods Following a baseline audit of oxygen prescribing, posters were introduced to promote and improve the prescription of oxygen. A second audit demonstrated that no improvement in adherence to guidelines had occurred. In response to this, a Trust wide oxygen policy, development of an oxygen sticker and a comprehensive multi-disciplinary educational programme was delivered, aimed at all medical, nursing, physiotherapy and pharmacy colleagues. The programme involved a series of practical sessions and presentations tailored to each discipline and delivered by pharmacy, physiotherapy and medical representatives. To assess the impact of the interventions, prospective data was collected assessing patients on oxygen against the following criteria:

- Has oxygen been prescribed?

If so, have the following been indicated:

- Target saturations

- Starting device and flow rate

- Continuous or when required oxygen

- Signed and dated by doctor

- Nurse signature for administration

- Clinically screened by pharmacist

Results The baseline audit demonstrated that oxygen was prescribed in only $23 \%$ of cases, of these $50 \%$ had target saturations prescribed. All those with an oxygen prescription had regular saturations and administration of oxygen recorded. Re-audit following introduction of educational posters demonstrated only $6 \%$ of patients had oxygen prescribed and target saturations documented $(\mathrm{n}=1)$. On delivery of the educational programme, a further audit recruited 563 patients, of which 83 patients (15\%) were administered oxygen, 30 (36\%) had oxygen prescribed appropriately, $73 \%$ with target saturations and $77 \%$ of which used the newly designed oxygen sticker (Abstract P84 Table 1).

Conclusions We have demonstrated that when changing clinical practice educational posters alone were not effective, however, a structured multidisciplinary teaching programme improved the prescription of oxygen to above national standards. Whilst further improvement is required, a rolling educational programme may further support this.

\section{REFERENCES}

1. British Thoracic Society. Emergency Oxygen Guideline Group. Guideline for emergency oxygen use in adults. Thorax 2008;63:vi1-68. http://thorax.bmj.com/content/63/ Suppl 6/vi1 (accessed 28.04.2010).

2. National Patient Safety Agency Oxygen safety in hospitals-rapid response report. 2009. http://www.nrls.npsa.nhs.uk/alerts/?entryid45=62811 (accessed 28.04.2010)

3. British Thoracic Society. Emergency oxygen audit results, 2009.

\section{P85 PICTORIAL REPRESENTATION OF RESPIRATORY EXAMINATION IN HOSPITAL NOTES}

doi:10.1136/thx.2010.150979.36

N Mahmood, C Gobbett, S Malik, C Houghton, G N G Man Kwong. Fairfield General Hospital, Pennine Acute Hospitals NHS Trust, Bury, UK

Good record keeping maximises patient safety and quality of care. The Royal College of Physicians recommends that 'medical records should have a standardised structure and layout' (RCP Generic Record Keeping Standards 2007). Pictorial representation of respiratory examination using a cartoon of the lungs annotated with lines, squiggles, crosses and musical notes is commonplace despite lack of standardisation and formal teaching. Our study aimed to assess the accuracy of interpretation and the rationale behind use of pictorial representation.

Methods Questionnaire survey correlating six common pictorial representations $\mathrm{A}-\mathrm{F}$ (see Abstract P85 Figure 1) with clinical findings as follows: $1=$ coarse crepitations, 2 =wheeze, $3=$ bronchial breath sounds, $4=$ decreased bronchial sounds, $5=$ pneumonectomy, $6=$ pleural effusion, $7=$ rhonchi, $8=$ fine end inspiratory crepitations, $9=$ bibasal crepitations, $10=$ transmitted upper airway sounds, $11=$ absent breath sounds, $12=$ pneumothorax, $13=$ other(specify) Multiple responses were allowed for the same picture.
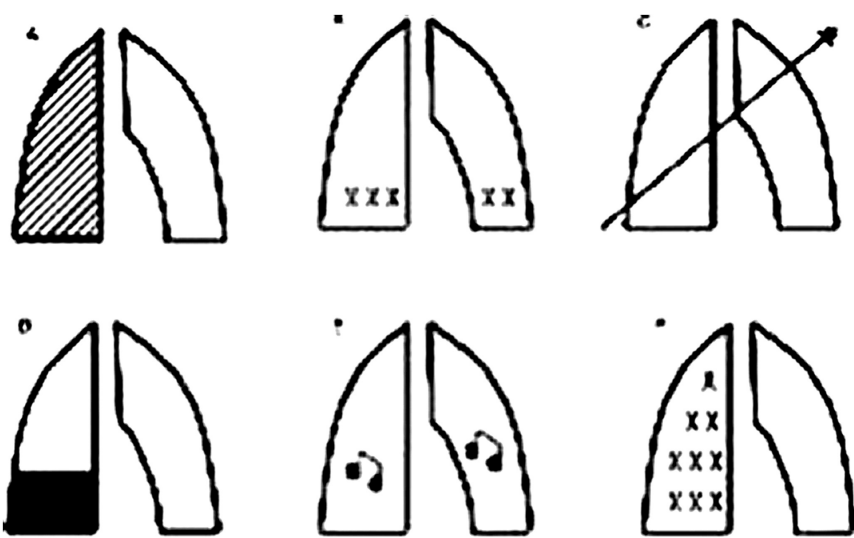

Abstract P85 Figure 1

Results 88 clinicians completed the survey (Foundation Year $n=44$, Specialist Trainee $\mathrm{n}=10$, Specialist Registrar $\mathrm{n}=13$, Consultant $\mathrm{n}=16$, other $\mathrm{n}=3) .74 / 88(84 \%)$ admitted to routinely drawing pictures. Of these $71 / 74(96 \%)$ also recorded findings in written text. $23 / 71(32 \%)$ could not provide a reason for their use of drawings

Abstract P84 Table 1 Results of three audits carried out and comparison with national standards

\begin{tabular}{|c|c|c|c|c|c|c|c|c|}
\hline & $\begin{array}{l}\text { Oxygen prescribed } \\
\text { (in patients } \\
\text { receiving oxygen) }\end{array}$ & $\begin{array}{l}\text { Prescribed using the } \\
\text { oxygen sticker }\end{array}$ & $\begin{array}{l}\text { Target saturations } \\
\text { indicated }\end{array}$ & $\begin{array}{l}\text { Device \& } \\
\text { flow rate } \\
\text { indicated }\end{array}$ & $\begin{array}{l}\text { Continuous or } \\
\text { when required } \\
\text { oxygen indicated }\end{array}$ & $\begin{array}{l}\text { Signed \& } \\
\text { dated by the } \mathrm{Dr}\end{array}$ & $\begin{array}{l}\text { Signed by } \\
\text { nurse for } \\
\text { administration }\end{array}$ & $\begin{array}{l}\text { Clinically screened } \\
\text { by the pharmacist }\end{array}$ \\
\hline 1st Audit January 2009 & $23 \%$ & NA & $50 \%$ & $0 \%$ & $100 \%$ & NA & $50 \%$ & NA \\
\hline 2nd Audit August 2009 & $6 \%$ & NA & $0 \%$ & $0 \%$ & $100 \%$ & NA & $0 \%$ & NA \\
\hline 3rd Audit June 2010 & $36 \%$ & $77 \%$ & $73 \%$ & $40 \%$ & $20 \%$ & $50 \%$ & $37 \%$ & $60 \%$ \\
\hline National Standards 2009 & $18.4 \%$ & $69 \%$ & $40 \%$ & $62 \%$ & $74 \%$ & NA & $27 \%$ & NA \\
\hline
\end{tabular}


though 26/71(37\%) reported that it aided communication. Most learned their behaviour from senior colleagues (22/76), own observation (16/76) or medical school (27/76). The closest associations were for Pictures C (77/78 responses, 99\%=normal) and E (94/ $102,92 \%=$ wheeze/rhonchi combined). Crosses were commonly interpreted as crepitations in Pictures B $(89 / 101,88 \%=$ fine and bibasal combined) and $\mathrm{F}(66 / 94,70 \%=$ coarse $)$. Pleural effusion was most commonly linked to Pictures A (35/107, 33\%) and D (75/98, $77 \%)$ though both of these had an additional eight and four interpretations respectively.

Conclusion The majority of doctors use pictorial representation to record respiratory examination. Lack of standardisation leads to variation in annotation and potentially alternative interpretation by others. With the exception of Picture $\mathrm{C}$, the use of pictures alone is unreliable. Reassuringly for patient safety, most doctors also write down their findings. Pictorial representation is most often informally learned and appears to be well established in UK medical practice.

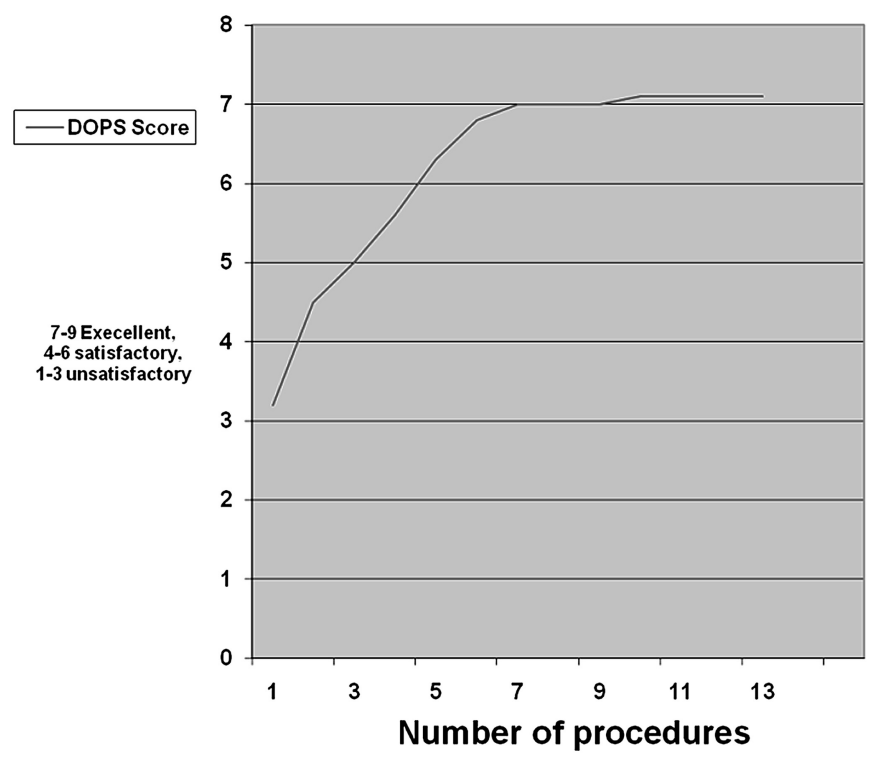

P87 EVIDENCE-BASED EMERGENCY OXYGEN GUIDELINES ARE NOT BEING FOLLOWED IN THE EMERGENCY DEPARTMENT

doi:10.1136/thx.2010.150979.38

${ }^{1} \mathrm{~S}$ M Wallace, 'L E Doy, 'E N Kedgley, ${ }^{2}$ W M Ricketts. ${ }^{1}$ Barts and The London School of Medicine and Dentistry, London, UK; ${ }^{2}$ Homerton University Hospital NHS Foundation Trust, London, UK

Introduction and objectives The first Emergency Oxygen Guidelines were published by the BTS in October $2008^{1}$ and were endorsed by 21 professional bodies, including the College of Emergency Medicine. The 2009 BTS audit ${ }^{2}$ showed improvement in the use of target saturations in the inpatient setting. We are concerned that uptake has been less impressive in the emergency department (ED).

Methods A retrospective cohort study was performed in a London Hospital of patients aged 16-70 attending the ED. Three time periods were chosen; immediately prior to and after guideline publication (1/7/08-30/9/08 and $1 / 11 / 08-31 / 1 / 09$, respectively) and 18 months after publication (1/4/10-30/6/10). Oxygen use was reviewed for all patients attending the $\mathrm{ED}$ with acute coronary syndromes (ACS), stroke, transient ischaemic attack (TIA) or with a known diagnosis of COPD. Patients requiring emergency intubation or on home long-term oxygen therapy (LTOT) were excluded Patients with known COPD with a diagnosis of ACS/stroke/TIA on that attendance were included in ACS/stroke/TIA category to avoid double counting.

Results A total of 253 individual attendances were reviewed. Initial observations of 58 (23\%) patients were performed on oxygen. Abstract P87 Table 1 summarises the use of oxygen in the groups studied.

Conclusions Oxygen is frequently used inappropriately in the ED and there has been no improvement since the guideline publication. Excess use of oxygen is the most common reason for not following the guidelines. This is consistent with historical practice in the ACS/ stroke/TIA group, although there appears to be a non-significant $(\mathrm{p}=0.09)$ trend towards improvement. One third of COPD patients also inappropriately received excess oxygen. Many patients have their first recorded saturations performed on oxygen which may suggest that guideline adherence within the ambulance service is also sub-optimal. Uptake of the guidelines has not been as good as in the inpatient setting. This may be due to lack of awareness outside the medical specialities. This trust currently has no oxygen champion, and this appointment should improve the situation, as would a programme of education within the $\mathrm{ED}$, which we intend to instigate. larger group which is on going. What is clear is that close mentoring is essential to master the skill and Consultant time must be set aside formally to sustain the training programmes. 